\title{
Warping Parameters Influence on Warp Yarns Properties: Part 2: Warp Yarn Material and Cone position on Warping Creel
}

\section{Dorgham ME}

Department of Applied Arts, Helwan University, Cairo, Egypt

“Corresponding author: Dorgham ME, Department of Applied Arts, Helwan University, Cairo, Egypt, Tel: 202- 25569051; E-mail: ms.dorgham@yahoo.com

Rec date: Jul 21, 2014; Acc date: Aug 01, 2014; Pub date: Aug 10, 2014

Copyright: (c) 2014 Dorgham ME. This is an open-access article distributed under the terms of the Creative Commons Attribution License, which permits unrestricted use, distribution, and reproduction in any medium, provided the original author and source are credited.

\begin{abstract}
Warping is a low yield operation owing to the time needed for creeling; the creels are the frames on which the cones which feed the warper are pinned. The number of cones depends on the type of fabric to be produced. The yarns are wound side by side and parallel one another on the beam, Also keep in mind that the number of yarns per beam is in the hundreds or thousands and that there must, at least, be one supply package for each of these yarns, if possible with the same tension, so the cone position and their accessibility are two important factors for the operator.
\end{abstract}

This paper reports a study on producing 27 different material yarn samples by an indirect warping machine (Benninger, Ben-Ergotronic, Switzerland) used in part 1 with $(\mathrm{V})$ shaped creel, the samples of the yarn manufactured from three different material (Cotton, Spun polyester and Polyacrylic) In addition, three different yarn count 30/2, $16 / 2,8 / 2 \mathrm{Ne}$ for cotton, spun polyester and 40/2, 28/2, 14/2 Nm for Polyacrylic yarns under the same yarn pressure, with three different distances between warping drum and cone position on warping creel $4 \mathrm{~m}, 8 \mathrm{~m}$ and $12 \mathrm{~m}$ with the same warping speed were tests measuring tensile strength and elongation.

The results of measurements of warp yarn under study for tensile strength and elongation for deferent warp materials and position of cone installation on warping creel for the properties of the yarn through laboratory experiments and make classification of preference for operating under different warping yarn conditions

Keywords: Warping parameters; Yarn material; Warp yarn; Weaving machine; Warping Creel; Stationary jaws

\section{Introduction}

In warping machine used in a warp preparation process for a weaving machine, yarns drawn out from a multiplicity for yarn supply packages fitted to warper creels are taken up around a warper drum.

Therefore an extremely large number of the yarn supply package corresponding to the number of warps for the weaving machine are supported by the warper creels on vertical planes at such intervals that the yarns being drawn out do not interfere with each other, for instance, a thousand and several hundreds of packages to the creels has been performed manually by the worker, by one package at a time [1].

\section{Warping creel}

Before thinking about winding a specified number of yarns on a beam, first consider the problem of positioning the packages from which the yarn is taken in such a manner so as to facilitate the removal of yarn, it is logical, therefore, to build a frame of some sort to hold the packages this frame is known as a creel and its function is to hold the supply packages in a manner so as to facilitate warping to accomplish this purpose creels are equipped with package holders on which the supply packages are placed, tension devices to help maintain uniform tension throughout the creel, guides to direct charges created by the rubbing of the yarn against the various surfaces and stop motions to detect broken ends and/or empty packages [2].
Independently of the warping system, the threads are fed from bobbins placed on creels. The creels are simply metallic frames on which the feeding bobbins are fitted, they are equipped with yarn, the creel capacity is the parameter on which the number of warping sections or beam s depends, it should be as high as the installation type and planning permit, the usual creel capacity amounts today to 800-1200 bobbins [3].

A creel for supplying yarns from a plurality of respective packages to a take-up machine such as a warp winder has a support defining respective supply stations carrying the yarn packages, respective stationary brake elements on the supports at the stations each having a braking surface, respective tension-sensing deflectors at the stations, and guides for directing the yarns from the respective packages over the respective braking surfaces and around the respective deflectors. Respective movable jaws movable toward and away from the respective stationary jaws can be actuated via respective springs to press against the yarns on the respective surfaces with a force capable of varying smoothly and steplessly up to a relatively high nominal level corresponding to high tension in the respective yarn [4].

\section{The creel size}

The creel size is limited by two factors. The first of these is floor space. A creel must be housed in the building and therefore it necessarily uses some of the facilities of that building the second factor is the yarn itself. In theoretical discussions, yarn weight, especially for short lengths of yarn, is neglected. 
In considering a very large creel, it is obvious that some of the supply packages must be very much further away from the distance where the beam is being formed than others. Also, the yarn must be supported to keep it from dragging on the floor and tangling. Each support acts as a capstan tension device. Thus, it is important to keep the packages in a distance range where the effect of yarn weight and the effect of supports as tensioners may be neglected.

Hence the size and, therefore, the capacity of the creel are limited. In general, maximum creel capacity ranges from about 300 packages for very heavy yarns to 1400 packages for fine yarns [2].

\section{Warping creel performance}

Warping is a low yield operation owing to the time needed for creeling, various solutions have been conceived to minimize this time, by trying to perform the creeling of the full cones while the warper is running [5].

The section warping machine is used for making patterned warps for weaving machine, the arrangement of colored threads in the warp sheet as per design is achieved by stacking colored packages on the creel in a suitable format, in a creel of about (400) packages the translation of warp pattern into stacking of colored package is quite complicated and time consuming, any mistake in placement of colored package on the creel will make a wrong pattern on the weaving machine and it cannot be rectified [6].

For the creeling of dyed yarns, a programmable electronic system has been studied; a warning light indicates the position where the yarn of a certain color must be creeled, this allows a time saving of $60 \%$ in creeling and avoids patterning faults and double ends $[5,6]$.

Trolley creels have generally two series of trolleys: one in operation and one waiting for being creeled, this system is suitable for staple fiber yarns in counts ranging from $\mathrm{Nm} 10$ to Nm 140, for staple fiber yarns also mobile creels are used. These can be equipped with a series of trolleys for the transport of the reserve cones; as an alternative, two creels with stationary cone carrier frame are used together with the warper, in both cases the bobbins are creeled during warping.

Another solution employs swivel frames. While yarns are unwound from the bobbins placed in the inside of the creel, it is possible to creel at the outside of the creel the new lot of cones [5].

We can use parallel creel with swiveling package frame sections or $\mathrm{V}$ - creel with reversible frames for cotton, viscose, polyester/cotton blended yarns, wool colored, but for polypropylene and monofilaments we can use parallel creel with unrolling draw-off [7].

For luxury yarns and synthetic filaments the so-called magazine creels are used, which enable to creel two cones per creeling position and to piece head-tail end of two cones [5,7].

\section{The Experimental Work}

This paper reports a study on producing 27 different material yarn samples by an indirect warping machine (Benninger, Ben-Ergotronic, Switzerland) [8] used in part 1 [9] with V shaped creel, the samples of the yarn manufactured from three different material (Cotton, Spun polyester \& Polyacrylic).

In addition, three different yarn count 30/2,16/2, 8/2 $\mathrm{Ne}$ for cotton, spun polyester and 40/2, 8/2, 4/2 Nm for Polyacrylic yarns under the same yarn pressure, with three different distances between warping drum and cone position on warping creel $4 \mathrm{~m}, 8 \mathrm{~m}$ and $12 \mathrm{~m}$ with the same warping speed Tensile strength test and percentage elongation of the yarn after yarn warping were used to measure the rate of change in the physical properties of the yarn to reach the best operating conditions suitable for these kinds of threads.

\section{Tests applied to samples under study}

Yarn samples under study were tested for tensile strength and elongation at break using 48-02 Universal Tester 3KN-CT (five reading for each sample) according to ASTM -D 2256-02 [10], to evaluate the produced fabrics properties.

The following are the specification of samples under study and the testing results.

\begin{tabular}{|c|c|c|c|c|c|}
\hline \multirow[b]{2}{*}{$\begin{array}{l}\text { Sample } \\
\text { No. }\end{array}$} & \multicolumn{3}{|c|}{ Specifications } & $\begin{array}{l}\text { Tensile } \\
\text { strength }(\mathrm{Kg})\end{array}$ & $\begin{array}{l}\text { Elongation } \\
(\%)\end{array}$ \\
\hline & $\begin{array}{l}\text { Yarn } \\
\text { material }\end{array}$ & $\begin{array}{l}\text { Yarn } \\
\text { count } \mathrm{Ne}\end{array}$ & $\begin{array}{l}\text { Cone } \\
\text { distance } \\
\text { m }\end{array}$ & & \\
\hline 1 & \multirow{9}{*}{ Cotton } & \multirow{3}{*}{$30 / 2$} & 4 & $0.93 \pm 0.04$ & $26.12 \pm 2.03$ \\
\hline 2 & & & 8 & $0.92 \pm 0.04$ & $25.05 \pm 2.04$ \\
\hline 3 & & & 12 & $0.88 \pm 0.06$ & $25.17 \pm 1.73$ \\
\hline 4 & & \multirow{3}{*}{$16 / 2$} & 4 & $0.89 \pm 0.07$ & $32.73 \pm 1.81$ \\
\hline 5 & & & 8 & $0.84 \pm 0.07$ & $32.03 \pm 1.58$ \\
\hline 6 & & & 12 & $0.8 \pm 0.08$ & $32.4 \pm 1.77$ \\
\hline 7 & & \multirow{3}{*}{$8 / 2$} & 4 & $1.51 \pm 0.18$ & $37.43 \pm 1.71$ \\
\hline 8 & & & 8 & $1.51 \pm 0.16$ & $35.01 \pm 1.80$ \\
\hline 9 & & & 12 & $1.51 \pm 0.13$ & $35.7 \pm 1.96$ \\
\hline
\end{tabular}

Table 1: Specifications and results for the produced samples [1-9]

\begin{tabular}{|c|c|c|c|c|c|}
\hline \multirow[b]{2}{*}{$\begin{array}{l}\text { Sampl } \\
\text { e No. }\end{array}$} & \multicolumn{3}{|c|}{ Specifications } & $\begin{array}{l}\text { Tensile } \\
\text { strength } \\
(\mathbf{K g})\end{array}$ & $\begin{array}{l}\text { Elongation } \\
(\%)\end{array}$ \\
\hline & $\begin{array}{l}\text { Yarn } \\
\text { material }\end{array}$ & $\begin{array}{l}\text { Yarn } \\
\text { count } \mathrm{Ne}\end{array}$ & $\begin{array}{l}\text { Cone } \\
\text { distance } \mathrm{m}\end{array}$ & & \\
\hline 10 & \multirow{9}{*}{$\begin{array}{l}\text { Spun } \\
\text { Polyester }\end{array}$} & \multirow{3}{*}{$30 / 2$} & 4 & $1.4 \pm 0.11$ & $50.51 \pm 2.11$ \\
\hline 11 & & & 8 & $1.4 \pm 0.10$ & $48.34 \pm 1.79$ \\
\hline 12 & & & 12 & $1.29 \pm 0.09$ & $49.07 \pm 1.98$ \\
\hline 13 & & \multirow{3}{*}{$16 / 2$} & 4 & $1.51 \pm 0.15$ & $49.63 \pm 1.91$ \\
\hline 14 & & & 8 & $1.51 \pm 0.11$ & $49.07 \pm 1.83$ \\
\hline 15 & & & 12 & $1.43 \pm 0.14$ & $49.46 \pm 2$ \\
\hline 16 & & \multirow{3}{*}{ 2-Aug } & 4 & $1.5 \pm 0.13$ & $55.98 \pm 2.01$ \\
\hline 17 & & & 8 & $1.51 \pm 0.13$ & $54.33 \pm 1.65$ \\
\hline 18 & & & 12 & $1.51 \pm 0.14$ & $55.65 \pm 1.88$ \\
\hline
\end{tabular}

Table 2: Specifications and results for the produced samples 
Page 3 of 6

\begin{tabular}{|c|c|c|c|c|c|}
\hline \multirow[b]{2}{*}{$\begin{array}{l}\text { Sampl } \\
\text { e No. }\end{array}$} & \multicolumn{3}{|c|}{ Specifications } & $\begin{array}{l}\text { Tensile } \\
\text { strength } \\
\text { (Kg) }\end{array}$ & $\begin{array}{l}\text { Elongation } \\
(\%)\end{array}$ \\
\hline & $\begin{array}{l}\text { Yarn } \\
\text { material }\end{array}$ & $\begin{array}{l}\text { Yarn count } \\
\mathrm{Nm}\end{array}$ & $\begin{array}{l}\text { Cone } \\
\text { distance m }\end{array}$ & & \\
\hline 19 & \multirow{9}{*}{$\begin{array}{l}\text { Poly } \\
\text { acrylic }\end{array}$} & \multirow{3}{*}{$40 / 2$} & 4 & $0.74 \pm 0.15$ & $81.33 \pm 1.95$ \\
\hline 20 & & & 8 & $0.72 \pm 0.13$ & $80.36 \pm 1.34$ \\
\hline 21 & & & 12 & $0.67 \pm 0.12$ & $81.4 \pm 1.82$ \\
\hline 22 & & \multirow{3}{*}{$28 / 2$} & 4 & $0.73 \pm 0.12$ & $115.18 \pm 1.63$ \\
\hline 23 & & & 8 & $0.67 \pm 0.1$ & $113.2 \pm 1.89$ \\
\hline 24 & & & 12 & $0.62 \pm 0.1$ & $114.42 \pm 1.74$ \\
\hline 25 & & \multirow{3}{*}{$14 / 2$} & 4 & $1.58 \pm 0.11$ & $121.13 \pm 1.92$ \\
\hline 26 & & & 8 & $1.62 \pm 0.1$ & $117.92 \pm 1.85$ \\
\hline 27 & & & 12 & $1.25 \pm 0.12$ & $119.81 \pm 1.89$ \\
\hline
\end{tabular}

Table 3: Specifications and results for the produced

\section{Result and Discussion}

\section{Tensile strength $(\mathrm{Kg})$}

As observed from the results in Tables 1-5 and Figures 1-3 it is obvious that the results of the tensile strength for the used raw materials are affected by the yarn's cone position on their dedicated creel on the warping machine. This can be witnessed from Figure 1 Which shows that the best reading recorded for the cotton yarn tensile strength was when the cone was at its nearest position on the creel from the warping drum, and that was true for all yarn thicknesses. By following the fixation distances it was found there was no perceived difference for yarns of counts $30 / 2$ and $8 / 2 \mathrm{Ne}$ when the cones were at 8 meters apart from the warping drum. In contrast, cotton yarns of $16 / 2$ Ne showed a marked decrease in its tensile strength reading when the cone was at its third position which equals to distance of 12 meters from the warping drum. Moreover, there was a decrease in the tensile strength readings for counts of $30 / 2$ and $16 / 2 \mathrm{Ne}$, whereas the readings for yarns of $8 / 2 \mathrm{Ne}$ were not affected at any of the three fixation distances. The decrease in tensile strength can be attributed to the longer passage that the yarn has to go through when the cone was fixed further away from the warping drum, which in turn leads to increased mechanical stress on the yarns due to friction with the guiding rings on the creel. In addition, the decreased yarn tensile strength may be attributed to the altering of the surface properties of the yarns which may lead to entanglements between adjacent yarns. The better withstanding of the $8 / 2 \mathrm{Ne}$ cotton yarns can be explained by the increase of the internal tensile strength forces of the yarn that has overcome the external forces surrounding the yarns during the warping process. This in turn led to the better withstanding to the external stresses regardless of its fixation distance on the creel. By observing Figure 2 for the PET spun yarns it was clear that tensile strength reading for the first two fixation distances $4 \mathrm{~m}$ and 8 meters for all yarn counts were the same. This was not true for the third fixation distance of 12 meters as there was a marked decrease in tensile strength for counts of $30 / 2$ and $16 / 2 \mathrm{Ne}$, while yarn count of $8 / 2 \mathrm{Ne}$ was not adversely affected. The decreased tensile strength for both $30 / 2$ and $16 / 2 \mathrm{Ne}$ counts can be attributed to the exact same aforementioned reasons discussed for the cotton yarns due to the spinning process used for the both yarn types with the exception that the polyester showed better tensile results than cotton yarns at $8 / 2 \mathrm{Ne}$ count for all three fixation distances. By observing Figure 3 for the polyacrylic spun yarns it was clear that tensile strength reading for the first fixation distance of 4 meters for all yarn counts resulted in the best tensile strength. But with going farther from the warping drum towards the second fixation distances there was a slight unperceived decrease in tensile strength for yarns of counts 40/2 and 28/2 Nm. On the other hand, there was a slight unperceived increase for the coarse yarns of $14 / 2 \mathrm{Nm}$ count. For the third fixation distance there was a decrease in tensile strength for all counts, especially for $14 / 2 \mathrm{Nm}$ polyacrylic yarns. This may be explained by the increase of the drafting effect on the yarns which in turn may affect the magnitude of elongation and deprive the internal air gaps from air content which is a characteristic feature of polyacrylic material. The aforementioned reasons may diminish its ability to withstand tensile stresses acting upon it; in addition the yarn thickness may be affected negatively due to the decrease air content discussed earlier.

Statistical analysis revealed that the best tensile strength results were achieved by the polyester spun yarns. This can be attributed to the marked internal tensile strength and its ability to withstand external surrounding stresses acting upon it. Counts of $8 / 2 \mathrm{Ne}$ and $14 / 2 \mathrm{Nm}$ recorded the highest tensile strength. Moreover, the first cone fixation distance of 4 meters from the warping drum also achieved the highest tensile strength results.

\begin{tabular}{|c|c|c|c|c|c|c|}
\hline Source & DF & Seq SS & Adj SS & Adj MS & $\mathbf{F}$ & P. Value \\
\hline Yarn Material & 2 & 5.91922 & 5.91922 & $\begin{array}{l}2.9596 \\
1\end{array}$ & $\begin{array}{l}219.1 \\
5\end{array}$ & 0 \\
\hline Yarn Count & 2 & 7.57056 & 7.57056 & $\begin{array}{l}3.7852 \\
8\end{array}$ & $\begin{array}{l}280.2 \\
8\end{array}$ & 0 \\
\hline Cone distance & 2 & 0.22711 & 0.22711 & $\begin{array}{l}0.1135 \\
6\end{array}$ & 8.41 & 0 \\
\hline $\begin{array}{l}\text { Yarn Material } \\
\text { Yarn Count }\end{array}$ & 4 & 2.94752 & 2.94752 & $\begin{array}{l}0.7368 \\
8\end{array}$ & 54.56 & 0 \\
\hline $\begin{array}{l}\text { Yarn Material } \\
\text { Cone distance }\end{array}$ & 4 & 0.09703 & 0.09703 & $\begin{array}{l}0.0242 \\
6\end{array}$ & 1.8 & 0.135 \\
\hline $\begin{array}{l}\text { Yarn Count } \\
\text { Cone distance }\end{array}$ & 4 & 0.02162 & 0.02162 & 0.0054 & 0.4 & 0.808 \\
\hline $\begin{array}{l}\text { Yarn Material* } \\
\text { Yarn Count* } \\
\text { Cone distance }\end{array}$ & 8 & 0.19961 & 0.19961 & $\begin{array}{l}0.0249 \\
5\end{array}$ & 1.85 & 0.076 \\
\hline Error & 108 & 1.45856 & 1.45856 & $\begin{array}{l}0.0135 \\
1\end{array}$ & & \\
\hline Total & 134 & 18.44124 & & & & \\
\hline $\mathbf{S}=0.116212$ & \multicolumn{4}{|c|}{$R-S q=92.09 \%$} & \multicolumn{2}{|c|}{$R-S q($ adj $)=90.19 \%$} \\
\hline
\end{tabular}

Table 4: Analysis of Variance for Tensile strength (Kg), using Adjusted SS for Tests

As for the relation between raw material type and cone fixation distance on the creel, the first fixation distance of 4 meters from the warping drum for cotton and polyacrylic yarns scored the highest tensile strength results. Whereas for the same relation polyester yarns scored the highest tensile strength result at a fixation distance of 8 
Page 4 of 6

meters. It has to be mentioned that this relation did not show any significant statistical differences.

\begin{tabular}{|l|l|l|l|l|l|l|}
\hline Source & DF & Seq SS & Adj SS & Adj MS & F & P. Value \\
\hline Yarn Material & 2 & 130599.1 & 130599.1 & 65299.5 & 19157.06 & 0 \\
\hline Yarn Count & 2 & 8158.7 & 8158.7 & 4079.3 & 1196.76 & 0 \\
\hline Cone distance & 2 & 60.1 & 60.1 & 30.1 & 8.82 & 0 \\
\hline $\begin{array}{l}\text { Yarn Material* } \\
\text { Yarn Count }\end{array}$ & 4 & 6186.6 & 6186.6 & 1546.6 & 453.74 & 0 \\
\hline $\begin{array}{l}\text { Yarn Material* } \\
\text { Cone distance }\end{array}$ & 4 & 3.9 & 3.9 & 1 & 0.28 & 0.888 \\
\hline $\begin{array}{l}\text { Yarn Count* } \\
\text { Cone distance }\end{array}$ & 4 & 7.7 & 7.7 & 1.9 & 0.57 & 0.688 \\
\hline $\begin{array}{l}\text { Yarn Material* } \\
\text { Yarn Count } \\
\text { Cone distance }\end{array}$ & 8 & 8 & 8 & 1 & 0.29 & 0.967 \\
\hline Error & 108 & 368.1 & 368.1 & 3.4 & & \\
\hline Total & 134 & 145392.2 & & R-Sq=99.75\% & & \\
\hline S=1.84625 & & & & & & \\
\hline
\end{tabular}

Table 5: Analysis of Variance for Elongation (\%), using Adjusted SS for Tests

\section{Elongation (\%)}

As observed from the elongation \% results in Tables 1-5 and Figures 1-3 for tested warp yarns and its relation to yarn thickness and raw materials, it can be concluded that those yarns are affected by varying the cone fixation distance on the cone creel during the warping process. Elongation \% readings reveal that there is a non-absolute inversely proportional relation between elongation \% readings and cone fixation distance from the warping drum for all tested material types. From Figure 4 It can observed that cotton yarns showed the highest elongation \% when the cones were fixed at the closed fixation distance of 4 meters from the warping drum. As the fixation distance grows apart from the warping drum, the elongation \% decreases and then starts to slightly increase again. The decrease in the elongation \% for the cotton yarns may be attributed to the increased drafting path effect on the warp yarns on the creel the farther the fixation distance from the warping drum. This in turn increases the stresses acting upon the warp yarns and leads to the increase in the elongation \% of the internal fibers within the yarn, and also to the increase of fiber slippage within the yarns which affects adversely its ability to withstand elongation and tensile stresses during the following weaving processes.

From Figure 5 It can observed that all polyester yarns showed the highest elongation $\%$ when the cones were fixed at the closed fixation distance of 4 meters from the warping drum. In that regard yarns of $16 / 2 \mathrm{Ne}$ count scored the best elongation \% results regardless of the fixation distance, followed by $8 / 2 \mathrm{Ne}$ and $30 / 2 \mathrm{Ne}$ respectively. It was also noticed that varying in the elongation $\%$ for the second and third fixation distances was minimal.

From Figure 6 it can observe that all polyacrylic yarns showed almost no change in elongation \% for all counts regardless of their fixation distance. This can be attributed the increased natural elasticity and elongation of the polyacrylic fibers, which in turn leads to its improved resistance against the induced stress caused by the increased drafting path due to the longer fixation distance. It can be concluded from elongation \% shown in Figures 4,5 and 6 for all tested fiber types and counts that the best cone fixation distance is at 4 meters, which is the closest to the warping drum. Moreover, when the number of cones increases on the creel it was found that is better to place the cones starting from the second fixation distance of 8 meters or more where the elongation \% do not differ a lot. This is especially true for both cotton and polyacrylic yarns.

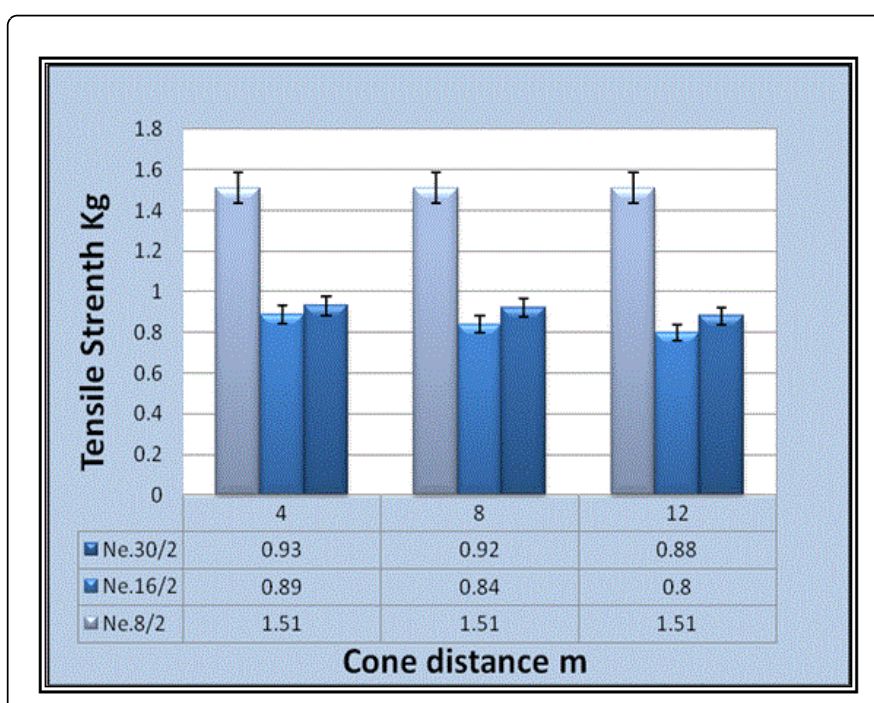

Figure 1: the relationship between tensile strength and distances between warping drum and cone position on warping creel at constant of the warp cotton yarn material.

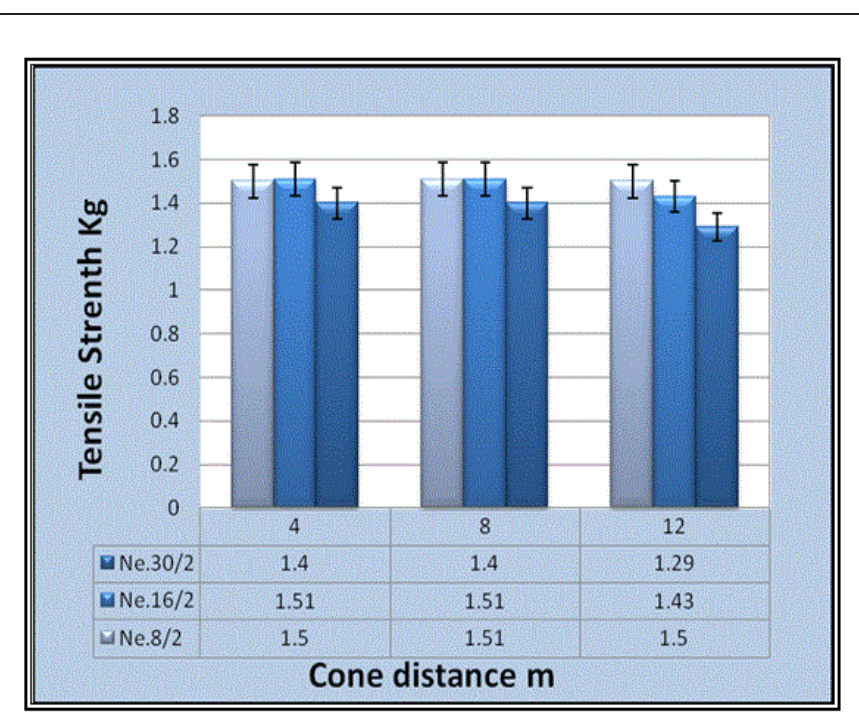

Figure 2: the relationship between tensile strength and distances between warping drum and cone position on warping creel at constant of the warp spun polyester yarn material. 


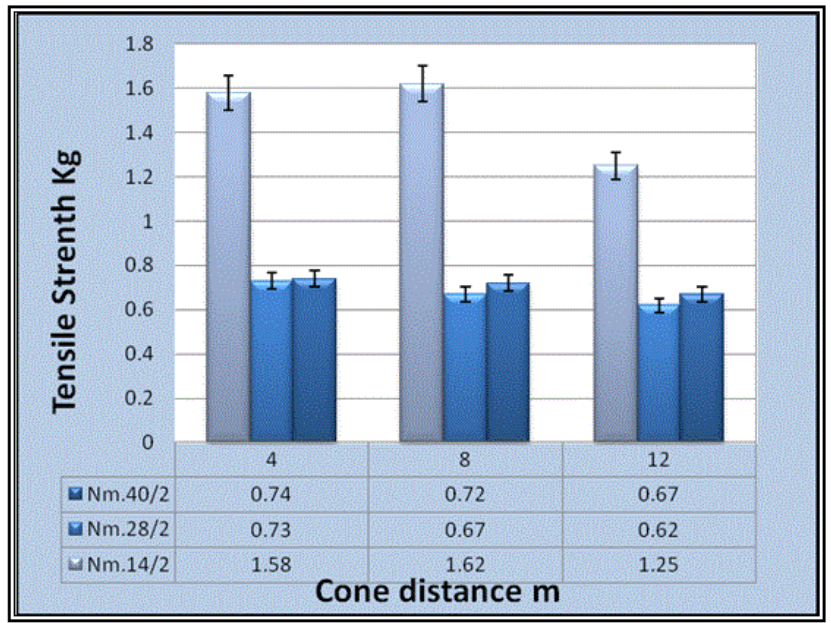

Figure 3: the relationship between tensile strength and distances between warping drum and cone position on warping creel at constant of the warp Polyacrylic yarn material.

Statistical analysis shows that the best elongation \% result was for the polyacrylic due its characteristic internal elongation properties and high air content between the fibres within the yarns. Moreover, the best elongation \% was for the coarse yarns of a count of $14 / 2 \mathrm{Nm}$. In addition the highest elongation $\%$ readings were achieved for cones at a distance of 4 meters from the warping drum for all yarn types.

As for the relation between the fixation distance on the creel and yarns type, it was found that the first fixation distance of 4 meters scored the lowest elongation, but this relation was not proven to statistically significant.

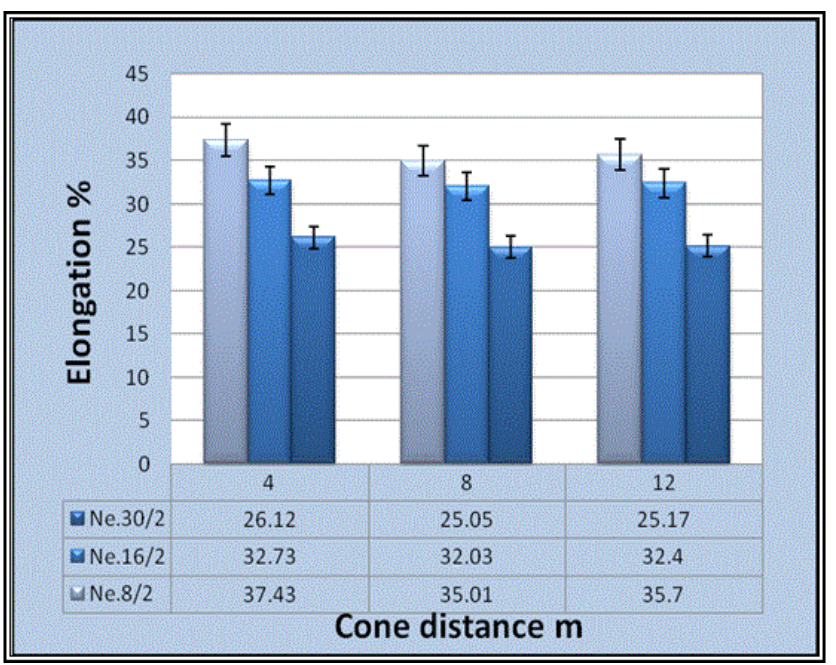

Figure 4: the relationship between elongation and distances between warping drum and cone position on warping creel at constant of the warp cotton yarn material.

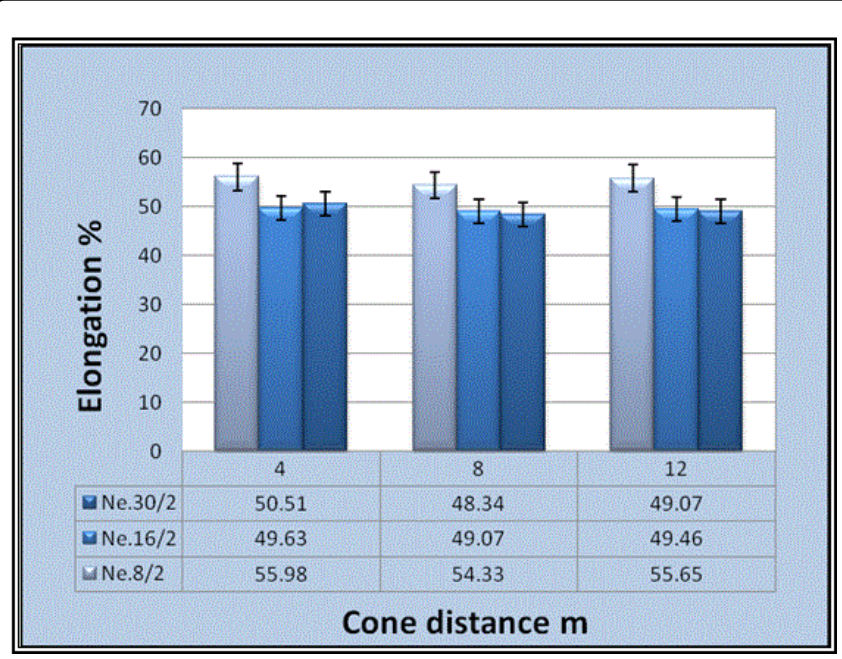

Figure 5: the relationship between tensile strength and distances between warping drum and cone position on warping creel at constant of the warp spun polyester yarn material.

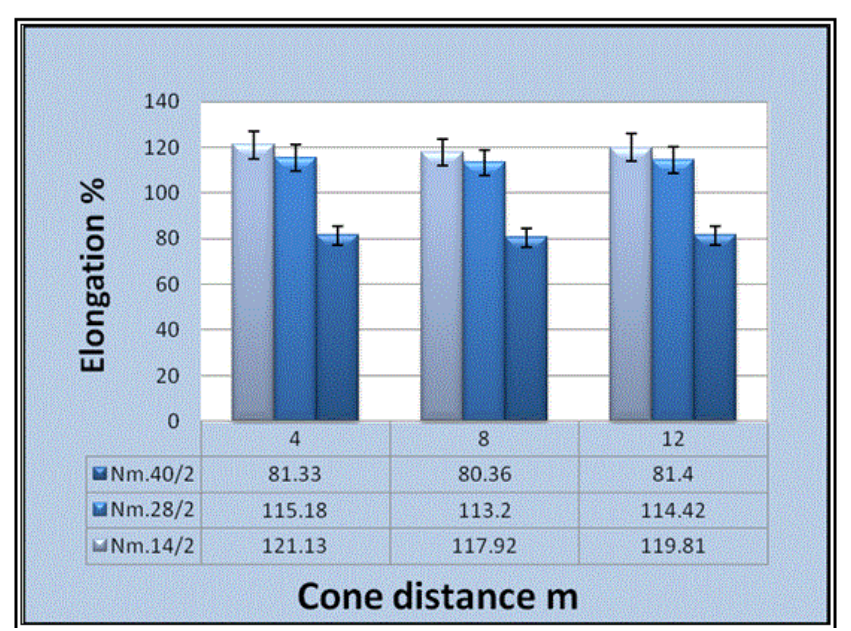

Figure 6: the relationship between tensile strength and distances between warping drum and cone position on warping creel at constant of the warp Polyacrylic yarn material.

\section{Conclusion}

It can be concluded that there are no analytical significant differences between warp yarns material type and the fixation distance of the cones on the creel from the warping drum. Having said that, it was found that there is an operational advantage of having the cones placed at the nearest point to the warping drum. As a result it is advised to increase the height of the cone creels and its rows (keeping in mind the human ergonomics) to increase its capacity while at the same time preserving its closeness to the warping drum, taking into consideration the spacing between the cones fixation points on the creel. This is especially important for short spun yarns which are characterized by small yarn packages when compared to yarn packages of continuous fibers with their large sizes and weight. 
Citation: Dorgham ME (2014) Warping Parameters Influence on Warp Yarns Properties: Part 2: Warp Yarn Material and Cone position on Warping Creel . J Textile Sci Eng 4: 164. doi:10.4172/2165-8064.1000164

Page 6 of 6

\section{References}

1. Nagasawa I (1987) Device for supplying packages to warper creels. US patent - 4669942

2. Panda H, Panda R (2006) yarn preparation. Devashish consultants (P) ltd.

3. Giovanni C, Salvatore M, Giuseppe S, Ivo Matteo S (2000) Weaving Reference Book of Textile Technologies. Italian Association of Textile Machinery Producers, Milano, Italy.

4. Kohlen, Karl-Heinz (1987) Creel for warping machine. US patent 4664335 .

5. ACIMIT (2000) The Italian textile machinery industry, today: characteristics, raw materials, technologies. Published for technical highschools.
6. Hari PK, Behera BK (2008) Computer controlled warp patterning on sectional warping machine. Indian journal of fiber \& textile research 33: 318-325.

7. Adanur S (2001) Handbook of Weaving. Technomic Publishing Company, Inc Lancaster, Pennsylvania, USA.

8. Benninger, Benninger Ben-Ergotronic (1996) Warping Machine Setting Instruction.

9. Dorgham ME (2013) Warping Parameters Influence on Warp Yarns Properties: Part 1: Warping Speed \& Warp Yarn Tension. J Textile Sci Eng 3.

10. ASTM (2014) Standard Test Method for Tensile Properties of Yarn by the Single-Strand Method. 